\title{
GRAIN GROWTH IN POLAR ICE: I. THEORY
}

\author{
By R. B. Alley, \\ (Geophysical and Polar Research Center, Department of Geology and Geophysics, \\ University of Wisconsin - Madison, Madison, Wisconsin 53706, U.S.A.) \\ J. H. PEREPEZKo, \\ (Department of Metallurgical and Mineral Engineering and Materials Science Program, \\ University of Wisconsin - Madison, Madison, Wisconsin 53706, U.S.A.) \\ and C. R. BENTLEY \\ (Geophysical and Polar Research Center, Department of Geology and Geophysics, \\ University of Wisconsin - Madison, Madison, Wisconsin 53706, U.S.A.)
}

\begin{abstract}
Many observations regarding grain growth in ice sheets are glaciologically interesting but imperfectly understood. Here we develop the theory of grain growth in ice that is not deforming rapidly, and in the succeeding paper we use this theory to explain observations from glacial ice. In the absence of significant strain energy, the driving force for grain growth arises from grain-boundary curvature. Grain growth is slowed by the interaction of grain boundaries with extrinsic materials (microparticles, bubbles, and dissolved impurities). If the driving force for growth is not large enough to cause boundaries to separate from an extrinsic material, then the grain-boundary velocity is determined by the velocity characteristic of the extrinsic material (low-velocity regime). If the driving force is large enough to cause separation, then boundaries migrate more rapidly than the extrinsic material (high-velocity regime) but the net driving force is reduced through transient pinning by the extrinsic material. Polar ice is typically in the low-velocity regime relative to dissolved impurities and the high-velocity regime relative to microparticles and bubbles. Cross-sectional area of grains is predicted to increase linearly with time under most but not all circumstances.
\end{abstract}

RÉSUMÉ. Croissance des grains dans la glace polaire: I. Théorie. De nombreuses observations sur la croissance des grains dans les calottes polaires sont intéressantes du point de vue glaciologique mais pas encore totalement élucidées. Nous développons ici une théorie de croissance des grains dans une glace à déformation faible et dans l'article suivant nous l'utilisons pour expliquer les observations obtenues sur ce type de glace. En l'absence d'énergie de déformation notable, la cause de croissance du grain provient de sa courbure de surface. La croissance du grain est diminué par l'intéraction de sa surface avec des matériaux extrinsèques (microparticules, bulles, et impuretés dissoutes). Si la force majeure de croissance n'est pas suffisante pour séparer la surface du matériel extrinsèque, alors la vitesse de la limite du grain est déterminée par la vitesse caractéristique du matériau extrinsèque (régime de vitesse lente). Au contraire

\section{SYMBOLS USED AND VALUES OF CONSTANTS}

$\begin{array}{cc}C_{\mathrm{b}} & \text { Grain-boundary impurity concentration } \\ C^{\mathrm{e}} & \begin{array}{c}\text { Eutectic composition for impurity-ice } \\ \text { system }\end{array}\end{array}$

si cette force est suffisante pour assurer la séparation, alors les limites migrent plus rapidement que le matériau (régime de fortes vitesses) mais la force principale est réduite à cause du pincement da au matériau extrinsèque. La glace polaire se situe typiquement dans un régime de basse vitesse vis à vis des impuretés dissoutes et dans un régime de fortes vitesses quant aux microparticules et aux bulles. On arrive à la conclusion qu'une section droite de grain s'accrô̂t linéairement en fonction du temps dans la plupart des situations.

ZUSAMMENFASSUng. Kornwachstum in polarem Eis: $I$. Theorie. Viele Beobachtungen zum Kornwachstum in Eisdecken sind glaziologisch interessant, aber ungenügend verstanden. Hier wird die Theorie des Kornwachstums in Eis, das sich nicht schnell verformt, entwickelt; im nächsten Beitrag wird diese Theorie zur Erklärung von Beobachtungen des Gletschereises herangezogen. Wenn keine signifikante Spannungsenergie vorhanden ist, entwickelt sich die Triebkraft für das Kornwachstum aus der Krümmung der Korngrenzflăchen. Das Kornwachstum wird durch die Wechselwirkung der Korngrenzflächen mit eingelagerten Materialien (Mikropartikel, Blasen, gelöste Verunreinigungen) verlangsamt. Ist die Triebkraft zum Wachstum nicht stark genug, um die Trennung zwischen Grenzflächen und eingelagertem Material zu bewirken, dann wird die Geschwindigkeit der Korngrenzflächen durch die charakteristische Geschwindigkeit des eingelagerten Materials bestimmt (Zustand der niedrigen Geschwindigkeit). Ist die Triebkraft gross genug, um Trennung zu verursachen, dann wandern die Grenzflächen schneller als das eingelagerte Material (Zustand der hohen Geschwindigkeit), doch wird die Netto-Triebkraft durch vorübergehendes Haften am eingelagerten Material verringert. Polareis befindet sich typisch im Zustand der niedrigen Geschwindigkeit relativ zu gelösten Verunreinigungen und im Zustand der hohen Geschwindigkeit relative zu Mikropartikeln und Blasen. Es lässt sich vorhersagen, dass die Querschnittsfläche von Körnern unter den meisten, aber nicht allen Umständen linear mit der Zeit zunimmt.
$C_{\mathrm{T}}$

$D_{\mathrm{b}}$
Average impurity concentration in bulk sample

Grain-boundary diffusivity of water molecules in ice $=5.68 \times 10^{-3}$ exp $\left[-6.93 \times 10^{-20} /(k T)\right] \mathrm{m}^{2} \mathrm{~s}^{-1}$, where we have set the activation energy to twothirds the value for lattice diffusion (Paterson, 1981, p. 18) 
$D_{\mathrm{b}}^{\prime}$

$D_{\mathrm{c}}$

$D_{\ell}$

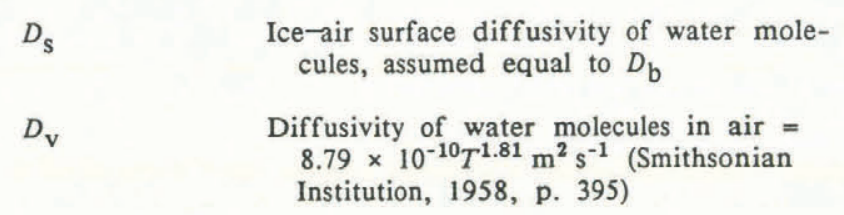

\section{$F_{\mathrm{b}}$}

$F_{\mathrm{p}}^{\prime}$

$F_{\mathrm{p}}$

$i$

$k$

$k_{0}$

$K, K^{\prime}, K^{*}$

$m$

$\mathrm{m}^{\prime}$

$M, M_{\mathrm{b}}, M_{\mathrm{e}}, M_{\mathrm{i}}$ Inverse of: general grain-boundary drag;

bubble drag; extrinsic grain-boundary drag; intrinsic grain-boundary drag

\section{$n_{\mathrm{p}}$}

Areal density of particles on grain boundary

$N_{\mathrm{b}} \quad$ Number of bubbles on each grain boundary

$P, P_{1}, P_{2}, P_{3}, P_{4}$ Driving force for grain-boundary migration under different conditions specified in text

$P_{0}$

Equilibrium vapor pressure over planar ice surface: $\log _{10} P_{0}=2-9.09718$ $\left(\left(\mathrm{T}_{0} / T\right)-1\right)-3.56654 \log _{10}\left(T_{0} / T\right)+$ $0.876793\left(1-\left(T / T_{0}\right)\right)+\log _{10} 6.1071$ where $T_{0}=273.16 \mathrm{~K}$ and $P_{0}$ is in $\mathrm{N} \mathrm{m}^{-2}$ (Smithsonian Institution, 1958, p. 350 )

$P_{\mathrm{b}}, P_{\mathrm{p}}, P_{\mathrm{s}}$

Drag force from: bubbles; microparticles; impurities

Bubble radius

Bubble radius at pore close-off

Microparticle radius

Average grain radius

Value of $R$ at time $=0$

Radius of grain that is neither growing nor shrinking

Radius of $j$ th grain in a sample

$R_{j}$

$R_{\mathrm{m}}, R_{\mathrm{m}}^{j}, R_{\mathrm{m}}^{\mathrm{b}}, R_{\mathrm{m}}^{\mathrm{p}} \quad$ Limiting size for grain growth in presence of: all extrinsic materials; $j$ th extrinsic material; bubbles, microparticles
$R^{\prime}$

$t$

$T$

$U$

$v$

$v_{\mathrm{b}}^{\mathrm{m}}$

$V_{\mathrm{p}}$

$\alpha$

$\alpha^{\prime}$

B

$\gamma, \gamma_{\text {AA }}$

$\gamma_{\mathrm{AB}}$

$\gamma_{\mathrm{s}}$

$\Delta x$

$\delta_{S}$

$\theta$

$\rho_{\mathrm{i}}$

$\rho_{\mathrm{V}}$

$\psi$

$\psi_{\ell}, \psi_{\mathrm{t}}$
Radius of curvature of grain-boundary section

Time

Absolute temperature

Impurity-boundary interaction energy

Grain-boundary velocity

Maximum steady-state bubble velocity

Microparticle volume fraction

Impurity/grain-boundary interaction parameter

Contact angle of boundary encircling particle

Correction factor for microparticle drag

Ice grain-boundary energy =

$0.065 \mathrm{~J} \mathrm{~m}^{-2}$ (Hobbs, 1974, p. 440)

Ice/extrinsic material surface energy

Ice-air surface energy $=0.109 \mathrm{~J} \mathrm{~m}^{-2}$

(Hobbs, 1974, p. 440)

Average diffusion distance across a bubble

Thickness of ice surface; also, $\frac{1}{2}$ grainboundary thickness $=4.5 \times 10^{-10} \mathrm{~m}$ (estimated as 1 Burger's vector; Hobbs, 1974, p. 22)

Microparticle/grain-boundary contact angle (Fig. 1)

Density of ice $=920 \mathrm{~kg} \mathrm{~m}^{-3}$ (Hobbs, 1974, p. $348-50)$

Density of water molecules in vapor

Equilibrium dihedral angle at bubble/ grain-boundary intersection

Angles between plane continuing grain boundary across bubble and leading, trailing edges of bubble

Molecular volume of water in ice $=$ $2.99 \times 10^{-26} \mathrm{~kg}$

\section{INTRODUCTION}

Grain-size in glacial ice is of interest because it controls many physical properties of ice and because it may record the age and past history of ice. As yet, however, we do not have a clear understanding of grain growth in glacial ice and some observations remain enigmatic. Here we review relevant theories for grain growth in dry, isothermal firn and glacial ice above the depth where significant flow deformation occurs and strong $c$-axis textures develop (roughly 10-1000 $\mathrm{m}$ depth in central Greenland or Antarctica); in the succeeding paper (Alley and others, 1986; hereafter referred to as paper II) we use the theories developed here to explain some observations regarding grain growth in natural glacial ice and to identify where further data are needed. We do not consider the more difficult problem of grain growth in deforming ice, which has been addressed by Duval (1984) and Duval and Lliboutry (1985), among others. We also do not consider grain growth in lowdensity firn in the presence of strong temperature gradients, which has been considered by Colbeck (1982), among others. 
In the depth region considered here, grain growth is driven only by grain-boundary curvature. Drag forces opposing grain growth in this region are caused only by inert second-phase particles (microparticles), bubbles, dissolved impurities, and the intrinsic drag of grain boundaries.

Many of the theories describing grain growth have been developed for metallurgical systems. There certainly are many atomistic differences between ice and metals; however, phenomenologic similarities are compelling, including Arrhenius-type temperature dependence of diffusivities, enhanced diffusion along grain boundaries, and segregation of dissolved impurities to grain boundaries. Also, theories for grain growth in metals have found wide application in the study of ceramics, which also show atomistic differences but phenomenologic similarities to metals. Thus, although it is incumbent upon us to exercise caution, we feel justified in applying to ice theories for grain growth in metals.

We follow the metallurgical convention of referring to crystals as grains. The two terms are essentially synonymous in the depth region considered here, although geometrically distinct units composed of two or more crystals each have been reported from shallow firn and have been termed grains (Gow, 1969).

We consider here the case of cold ice only. At temperatures above about $-10^{\circ} \mathrm{C}$, liquid and pseudo-liquid layers appear in natural ice and the behavior of the system changes. Grain growth in wet snow has been discussed by Colbeck (1979).

\section{INTRINSIC GRAIN GROWTH}

The general relation describing grain-boundary velocity, $v$, can be written as

$$
v=M P
$$

where $M$ is the grain-boundary mobility and $P$ is the driving force for grain-boundary migration (Higgins, 1974). The "driving force" actually has units of pressure and arises from a gradient in free energy, but we follow conventional usage in referring to it as force. The inverse of the mobility is the drag on grain-boundary migration. In the case where there are no extrinsic drag forces (no microparticles, bubbles, or dissolved impurities in the material), $M=M_{\mathrm{i}}$, the intrinsic grain-boundary mobility, and the driving force for migration of an isotropic, spherically curved section of grain boundary with radius of curvature $R^{\prime}$ is given by

$$
P_{1}=\frac{2 \gamma}{R^{\prime}}
$$

where $y$ is the grain-boundary energy or surface tension. (We use the letter $P$ to denote a driving force for grain growth. The numerical subscripts 1, 2, etc. identify the driving force for different conditions, e.g. with or without bubbles, with or without microparticles.) The value of the surface tension between adjacent grains, $\gamma$, does not depend on the relative orientation of the grains for most orientations, although it is reduced significantly if there is very low mismatch between lattices of adjacent grains or if adjacent grains are in certain restricted orientations with high densities of coincidence sites (Verhoeven, 1975, p. 208-09). We assume here that $y$ is the same for all surfaces in a sample, which is a good approximation in the absence of strong deformational fabrics (Colbeck, 1982).

Grains in fully consolidated, single-phase systems cannot be spherical, so Equation (2) must be modified to account for the actual geometry of materials. Many attempts have been made to do this, using both analytical (Hillert, 1965; Louat, 1974; Mullins, 1986) and numerical (Anderson and others, 1984, 1985; Srolovitz and others, 1984) techniques. Analytical techniques suffer from the necessity of oversimplifying the complex geometry of real materials; however, analytical models supply clear, easily interpretable results and allow further calculation. Numerical models offer the possibility of eventually modeling the true complexity of grain growth. Thus far, however, numerical models have been limited to two-dimensional or simplified three- dimensional systems and the results are not fully independent of the numerical scheme used. Also, numerical models do not yield analytical equations that can be used in further calculations.

We will study grain growth using the analytical model developed by Hillert (1965). Empirical, numerical, and analytical studies conducted since 1965 have shown that this model does not provide an exact description of grain growth (see Anderson and others, 1984; Srolovitz and others, 1984), but that it does provide an excellent first approximation. The reader should remember, however, that the theory of grain growth is not complete and that some of our conclusions may require refinement in the light of future advances.

The Hillert model is based on the observation that average grain-size in a material increases because small grains shrink and disappear while large grains grow. This implies that at any instant there must be some critical grain radius, $R_{\mathrm{cr}}$, such that all grains with longer radii are growing and all grains with shorter radii are shrinking. The length of this critical radius increases with time as the average grain-size increases. (The numerical experiments of Srolovitz and others (1984) confirm this in general but indicate that there is some random noise in the growth of large grains.) The simplest relation that gives growth of grains with radius $R_{j}>R_{\mathrm{cr}}$ and shrinkage of grains with $R_{j}<R_{\text {cr }}$ is

$$
\frac{\mathrm{d} R_{j}}{\mathrm{~d} t}=K^{\prime}\left(\frac{1}{R_{j}}-\frac{1}{R_{\mathrm{cr}}}\right)
$$

where $t$ is time and $K^{\prime}$ is a constant; Hillert (1965) based his model on this relation.

Observations of grain growth generally show that, after a short transient period, the grain-size distribution of a sample normalized by the mean grain-size of that sample does not vary with time. By using Equation (3) and requiring that the normalized grain-size distribution be steady, Hillert was able to derive the grain-growth law and steadystate grain-size distribution in terms of the critical radius. $\mathrm{He}$ was also able to express the critical radius in terms of the average radius, $R$. Using these results, the intrinsic driving force for grain growth in Equation (2) can be rewritten as

$$
P_{1}=\frac{16 \gamma}{81 R} .
$$

Hillert also noted that if Equation (1) is applied to bulk material, the velocity can be rewritten as

$$
v=\frac{\mathrm{d} R}{\mathrm{~d} t}
$$

Combining Equations (1) (with $M=M_{\mathrm{i}}$ ), (4), and (5), Hillert found that

$$
\frac{\mathrm{d} R}{\mathrm{~d} t}=\frac{K}{2 R}
$$

where

$$
K=2\left(\frac{16}{81}\right) \gamma M_{\mathrm{i}} \text {. }
$$

Equation (6) can be solved for $R$ to obtain

$$
R^{2}=R_{0}^{2}+K t
$$

where $R_{0}$ is the average grain radius at $t=0$. A graingrowth equation of this form but with a different value of $K$ was derived by Smith (1948) and was applied to glacial ice first by Gow (1969) and Stephenson (1967).

Virtually all theoretical and experimental treatments of grain growth conclude that grain-size distributions normalized by their means rapidly approach a steady state, and that in this steady state the growth law is at least approximated by the form

$$
R^{m}=R_{0}^{m}+K^{n} t
$$

where $K^{\prime \prime}$ and $m$ are constants (Anderson and others, 1984; 
Srolovitz and others, 1984). Values reported for $m$ typically range from 2 to 3 . Because the data for glacial ice are most consistent with $m=2$ (Gow and Williamson, 1976; Duval and Lorius, 1980) and because of the theoretical justification for $m=2$, we will use Equation (8) to describe grain growth and will follow previous workers in assuming that deviations from $m=2$ arise only from extrinsic effects (Grey and Higgins, 1973). The derivation of Equations (7) and (8) involved a number of assumptions and approximations; thus, the constant $(16 / 81)$ is likely to be somewhat inaccurate. We will use $(16 / 81)$ here but $(1 / 5)$ is sufficiently accurate for most purposes.

The intrinsic mobility, $M_{\mathrm{i}}$, is of ten expressed (Verhoeven, 1975, p. 209)

$$
M_{\mathrm{i}}=\frac{D_{\mathrm{h}}^{\prime} \Omega}{2 \delta_{\mathrm{s}} k T}
$$

where $D_{\mathrm{b}}^{\prime}$ is the diffusivity of water molecules across grain boundaries and shows an Arrhenius-type temperature dependence, $2 \delta_{\mathrm{s}}$ is the jump length of diffusing molecules ( $\approx$ grain-boundary thickness), $\Omega$ is the molecular volume, $k$ is Boltzmann's constant, and $T$ is absolute temperature. The diffusivity of water molecules across grain boundaries is of ten identified with the diffusivity along grain boundaries. We discuss the validity of this identification in the succeeding paper.

\section{EXTRINSIC EFFECTS ON GRAIN GROWTH}

If all ice were pure and fully densified, then Equation (8) would provide a complete description of steady-state grain growth driven by grain-boundary curvature. This is not the case, however, and we must consider the effects of extrinsic materials (microparticles, bubbles, and dissolved impurities) on grain growth. To do this, we will first present a general discussion of extrinsic effects, and then consider microparticles, bubbles, and dissolved impurities in turn, following the approach of Higgins (1974).

Extrinsic materials can interact with grain boundaries. In almost all cases the interaction energy causes the extrinsic materials to be concentrated on the boundaries, either by diffusion to boundaries or by interaction with migrating boundaries. Microparticles and bubbles replace boundary area, whereas impurities dissolve in boundaries.

The effect of extrinsic materials on the migration rate of grain boundaries is determined by the relative magnitudes of the intrinsic driving force for boundary migration and the force required to separate boundaries from extrinsic materials. If the intrinsic driving force exceeds the separation force, then boundaries will migrate away from extrinsic materials ("high-velocity regime"); after separation, the net driving force will be reduced slightly from its intrinsic value by further encounter with and separation from extrinsic materials (Higgins, 1974). If the intrinsic driving force is not sufficient to cause separation, then boundaries remain with the extrinsic materials and migrate at a velocity determined by the extrinsic materials ("lowvelocity regime"). Depending on the mobility of extrinsic materials, boundaries in the low-velocity regime may be fixed or may migrate rapidly; however, the transition to the high-velocity regime always increases migration rates.

In the high-velocity regime, the intrinsic driving force is reduced to the separation force from some extrinsic material, $j$, when the grain-size reaches the limiting size $R_{\mathrm{m}}^{j}$. During grain growth toward this limiting size, the net driving force is given by

$$
P_{2}=\frac{16 \gamma}{81}\left[\frac{1}{R}-\frac{1}{R_{\mathrm{m}}^{j}}\right]
$$

where $16 \gamma /(81 R)$ is the intrinsic driving force and $16 \gamma /\left(81 R_{\mathrm{m}}^{j}\right)$ is the separation force. Most evidence indicates that if several extrinsic materials are present in a sample, their separation forces are additive (Higgins, 1974). In the presence of $i$ different extrinsic materials, Equation (11) becomes

$$
P_{3}=\frac{16 \gamma}{81}\left[\frac{1}{R}-\frac{1}{R_{\mathrm{m}}}\right], \frac{1}{R_{\mathrm{m}}} \equiv \sum_{j=1}^{i} \frac{1}{R_{\mathrm{m}}^{j}} .
$$

Then, substituting Equation (12) into the general migration relation, Equation (1), we find

$$
\frac{\mathrm{d} R}{\mathrm{~d} t}=\frac{K}{2}\left(\frac{1}{R}-\frac{1}{R_{\mathrm{m}}}\right)
$$

where $K$ is again defined by Equation (7) and $\mathrm{d} R / \mathrm{d} t$ by Equation (5). The solution of this differential equation is

$$
R_{\mathrm{m}}\left(R_{0}-R\right)+R_{\mathrm{m}}^{2} \ln \left[\frac{R_{\mathrm{m}}-R_{0}}{R_{\mathrm{m}}-R}\right]=\frac{K}{2} t
$$

where $R_{0}$ is the value of $R$ at $t=0$.

Equation (14) is the general description of grain growth influenced by extrinsic materials, just as Equation (8) is the general description of intrinsic grain growth. In many cases, $R \gg R_{0}$. Then if $R_{\mathrm{m}} \gg R$ (little extrinsic drag) or if $R_{\mathrm{m}}$ is proportional to $R$ (which might occur if the volume fraction of some extrinsic material decreases as grains grow), extrinsic grain growth will mimic intrinsic growth in that grain area will increase linearly with time; however, grain growth will be slower than for intrinsic growth if $R_{\mathrm{m}}$ is significant but proportional to $R$. If extrinsic materials are present, $R_{\mathrm{m}}$ is of the same magnitude as $R$, and $R_{\mathrm{m}}$ does not vary directly with $R$, then Equation (14) shows that linear increase of grain area with time will not occur.

The drag forces discussed above are independent of grain-boundary velocity; however, some drag forces are directly proportional to velocity (Grey and Higgins, 1973). If the driving force, $P$, in Equation (1) is reduced by a drag force proportional to velocity, $v$, then Equation (1) becomes

$$
v=\frac{P-M_{\mathrm{e}}^{-1} v}{M_{\mathrm{i}}^{-1}}
$$

where $M_{\mathrm{e}}^{-1}$ is defined as the velocity-independent coefficient of the velocity-dependent drag force $M_{\mathrm{e}}^{-1} v$. Then algebraic manipulation of Equation (15) shows that

$$
v=\frac{P}{M_{\mathrm{i}}^{-1}+M_{\mathrm{e}}^{-1}} .
$$

We thus see that $M_{\mathrm{e}}^{-1}$ is the extrinsic grain-boundary drag just at $M_{\mathrm{i}}^{-1}$ is the intrinsic grain-boundary drag. Velocitydependent drag forces thus can be said to reduce boundary mobility. Then Equation (14) again applies, if we replace $M_{\mathrm{i}}$ in Equation (7) by $\left(M_{\mathrm{i}}^{-1}+M_{\mathrm{e}}^{-1}\right)^{-1}$.

\section{Microparticle drag}

The effect on grain growth of inert microparticles with incoherent interfaces was first quantified by Zener (in Smith, 1948) for metallic systems. Zener's theory has been considered further by Ashby and others (1969), Hellman and Hillert (1975), and Nes and others (1985). We will present Zener's derivation and then summarize improvements to it.

Microparticles are assumed to be spherical, uniformly distributed, of only one size which is small compared to grains, and to have zero mobility (Ashby and Centamore, 1968). If surface energy is independent of orientation of a surface, then the surface-tension balance at a triple junction (the intersection of three surfaces in a line) reduces to a balance of force vectors directed along the surfaces perpendicular to the line of intersection, with magnitudes equal to the surface tensions of the respective surfaces (Fig. 1; see Verhoeven (1975, chapter 7.2) for a more complete development). For a particle of material $B$ resting on a boundary between two grains of $A$, the particle-grain surface tensions cause equal and opposite forces (Fig. 1). 


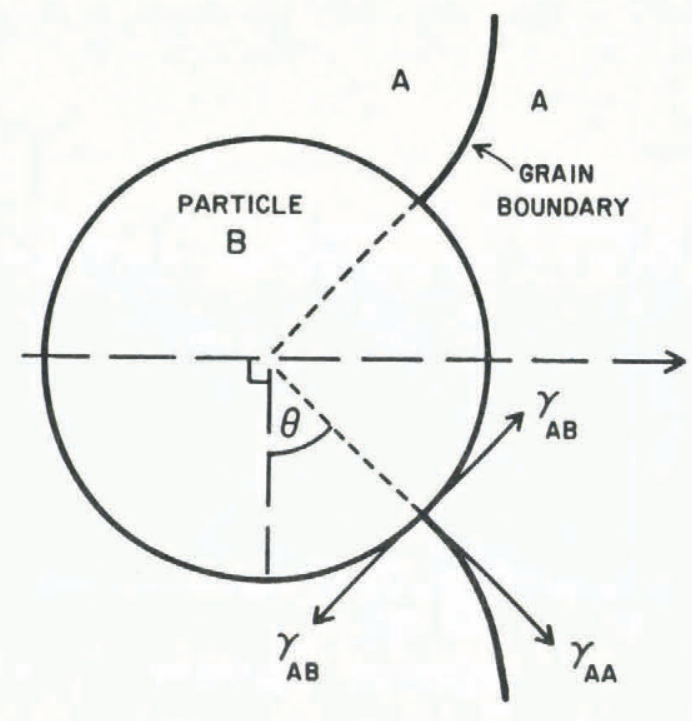

Fig. 1. Force balance in microparticle drag. A spherical particle of material $B$ rests on a moving boundary between two grains of $A$; the boundary is symmetric about the axis shown (dashed line) and moving in the direction indicated. Surface energies $\gamma_{\mathrm{AA}}$ and $\gamma_{\mathrm{AB}}$ act as forces along interfaces in the directions indicated.

The force of the boundary on the particle, and thus of the particle on the boundary, $F_{\mathrm{p}}^{\prime}$, then arises wholly from the AA surface tension, $\gamma_{\mathrm{AA}}$ or simply $\gamma . F_{\mathrm{p}}^{\prime}$ depends on the angle $\theta$ shown in Figure 1, according to

$$
F_{\mathrm{p}}^{\prime}=2 \pi r_{\mathrm{p}} \gamma \cos \theta \sin \theta
$$

where $r_{\mathrm{p}}$ is the particle radius. $F_{\mathrm{p}}^{\prime}$ is maximized for $\theta=$ $\pi / 4$, at which it has the value $F_{\mathrm{p}}$ given by

$$
F_{\mathrm{p}}=\pi r_{\mathrm{p}} \gamma \text {. }
$$

All particles with centers within $r_{\mathrm{p}}$ of a boundary on either side will be contacted by the boundary. If the particles are widely spaced (spacing greater than a few particle diameters), the boundary can bend so that each particle exerts its maximum force. If particles occupy volume fraction $V_{p}$ of the material and the number of particles in contact with unit area of boundary is denoted $n_{\mathrm{p}}$, then

$$
n_{\mathrm{p}}=\frac{V_{\mathrm{p}}}{\frac{4}{3} \pi r_{\mathrm{p}}{ }^{3}}\left(2 r_{\mathrm{p}}\right)
$$

The total drag force caused by microparticles per unit area of grain boundary, $P_{\mathrm{p}}$, is the product of the number of particles per unit area, $n_{\mathrm{p}}$, and the drag force per particle, $F_{\mathrm{p}}$, or

$$
P_{\mathrm{p}}=\frac{3}{2} \frac{V_{\mathrm{p}}}{r_{\mathrm{p}}} \gamma .
$$

The driving force for grain growth in the presence of microparticles only, $P_{4}$, is the intrinsic driving force, $P_{1}$ in Equation (4), reduced by the microparticle drag force, ${ }^{1} P_{\mathrm{p}}$. Thus

$$
P_{4}=\frac{16 \gamma}{81}\left[\frac{1}{R}-\frac{243 V_{\mathrm{p}}}{32 r_{\mathrm{p}}}\right] .
$$

If $P_{4}$ is greater than zero, then grain boundaries can separate from microparticles and grain growth occurs in the high-velocity regime shown in Figure 2a. When $P_{4}$ falls to zero, grain boundaries cannot escape from microparticles and grain growth ceases for inert microparticles (low-velocity regime; Fig. 2a).

We can define $R_{\mathrm{m}}^{\mathrm{p}}$ to be the grain radius at which the intrinsic driving force equals the microparticle drag force. Equation (21) then can be rewritten as

$$
P_{4}=\frac{16 \gamma}{81}\left[\frac{1}{R}-\frac{1}{R_{\mathrm{m}}^{\mathrm{p}}}\right] ; R_{\mathrm{m}}^{\mathrm{p}} \equiv \frac{32}{243} \frac{r_{\mathrm{p}}}{V_{\mathrm{p}}} .
$$

Equation (18) can be altered to allow for particle type and for enhanced bending of boundaries. The study of Ashby and others (1969) indicates that $F_{\mathrm{p}}$ should be multiplied by the factor $\left(1+\cos \alpha^{\prime}\right)$ where $\alpha^{\prime}$ is the contact angle between grain boundary and microparticle (taken to be $\pi / 2$ in Zener's derivation). This contact angle depends on the type of microparticle and the relative orientation of the particle and grains, and varies between 0 and $\pi / 2$. For widely spaced particles, Hellman and Hillert (1975) showed that a moving boundary will bend to remain in contact with more particles than assumed by Zener. To allow for this, they proposed that the value of $n_{\mathrm{p}}$ be multiplied by the factor $\beta$, which is given approximately by

$$
B=0.125 \ln \left(\frac{40 R^{\prime}}{r_{\mathrm{p}}}\right)
$$

where $R^{\prime}$ is again the radius of curvature of the section of boundary under consideration. The factor $B$ will vary between 1 and 2 in most cases.

The drag effect of particles is probably overestimated by these calculations, however, as discussed by Hellman and Hillert (1975). First, some particles may exert less than their maximum effect. Also, a moving boundary will experience an added driving force (negative drag force) upon first encountering a particle. In the light of these factors and the uncertainty involved in the constants in $P_{\mathrm{p}}$, we follow Hellman and Hillert (1975) in taking

$$
P_{\mathrm{p}}=\frac{4 \gamma}{9} \frac{V_{\mathrm{p}} \mathrm{B}}{r_{\mathrm{p}}}
$$

and taking $B$ to be identically 1 . Then the ratio of the particle drag force to the intrinsic driving force is

$$
\frac{P_{\mathrm{p}}}{P_{1}}=\frac{9}{4} \frac{V_{\mathrm{p}} R}{r_{\mathrm{p}}}
$$

The constant $4 / 9$ in Equations (24) and (25) is probably somewhat inaccurate, but it is unlikely to underestimate particle drag. We can also be confident that microparticle drag is directly proportional to the volume fraction of particles and inversely proportional to the particle radius. If particles of different radii are present, then the total particle-drag force is the integral of Equation (24) over all particles in the sample.

Finally, Hellman and Hillert (1975) pointed out that, if the volume fraction of microparticles is near or above $10 \%$, many particles will fall on triple junctions where they exert less drag force on grain-boundary migration. The factor $\beta$ is thus significantly less than 1 at large particle concentrations, although its exact value has not been calculated.

\section{Bubble drag}

Bubbles that are small compared to the grain-size cause drag in the same way as microparticles, except that bubbles are mobile in the low-velocity regime. Continuous porosity and large bubbles cannot separate from boundaries to grain interiors, but can cause drag through the action of thermal grooves and intergranular necks.

We first consider bubble-boundary separation, which is the transition from low-velocity to high-velocity migration relative to bubbles. If the chemical potential of material in contact with a bubble varies across the bubble (owing to different curvatures on opposite sides of the bubble, 

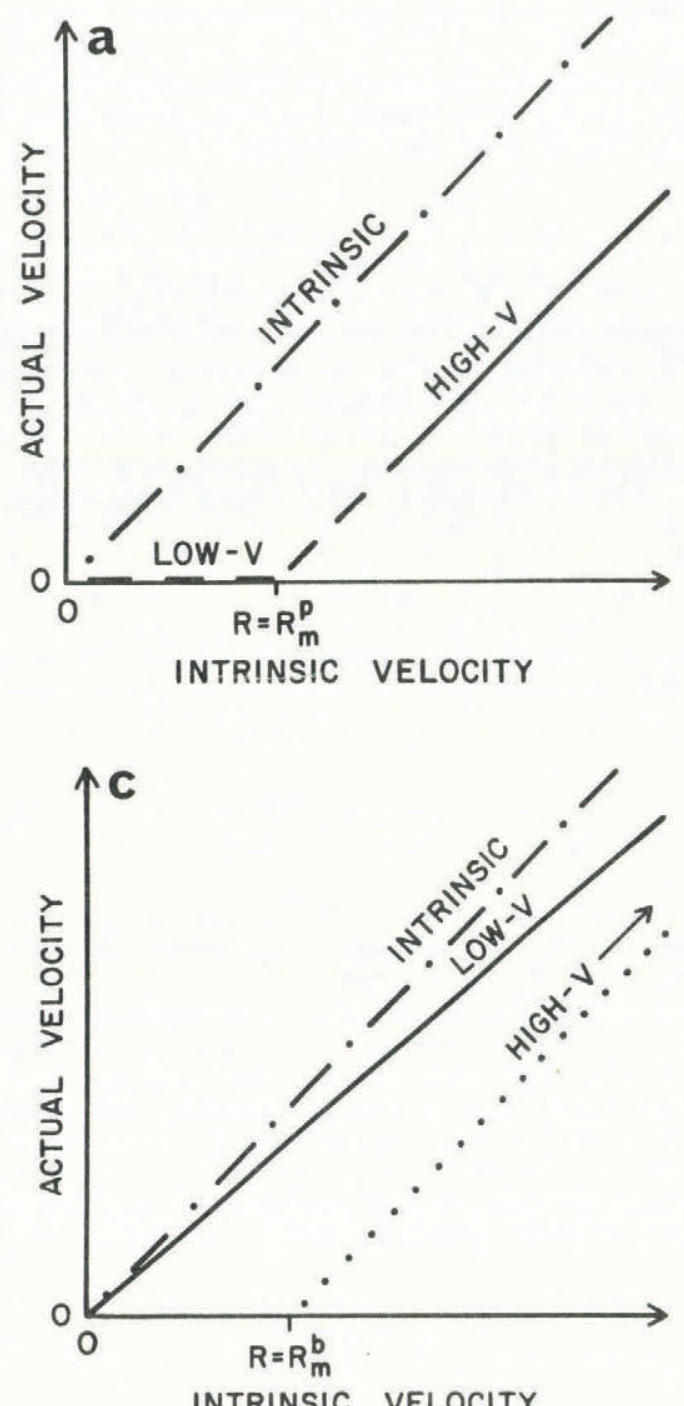
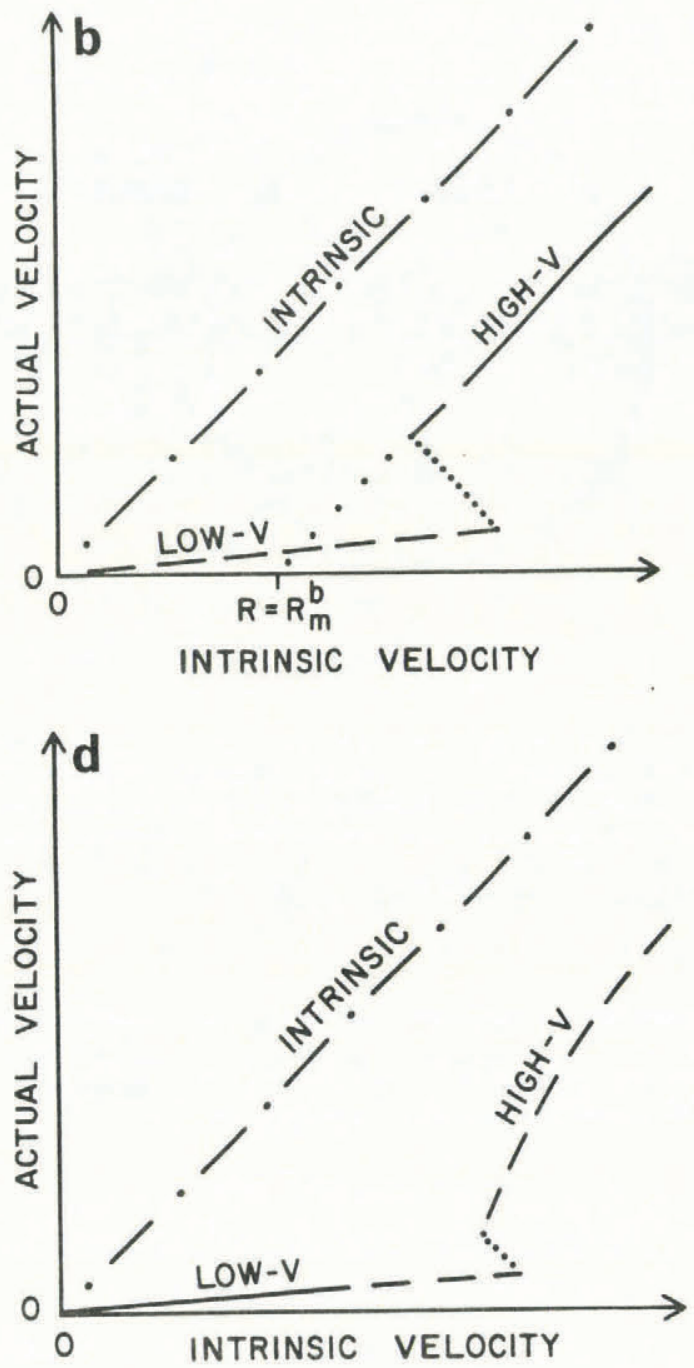

Fig. 2. Relation between intrinsic grain-boundary velocity and velocity in the presence of extrinsic materials in ice. Solid lines indicate behavior likely to occur in natural systems; dashed lines indicate behavior unlikely in Nature but theoretically possible; dotted lines indicate unstable behavior; and dot-dash lines show intrinsic behavior. (a) Behavior in the presence of microparticles only. (b) Behavior in the presence of low-mobility porosity (bubbles in ice) only. (c) Behavior in the presence of high-mobility porosity (small necks and thermal grooves in firn) only. Notice that transition from low-velocity to high-velocity migration occurs at higher velocities than shown in the figure and involves an increase in velocity. (d) Behavior in the presence of dissolved impurities only.

imposed temperature gradients, or other factors), then material will diffuse across the bubble and the bubble will migrate. Diffusion may occur through the bubble (vapor diffusion, with diffusivity $D_{\mathrm{v}}$ ), along the bubble surface (surface diffusion, $D_{s}$ ), or through the material around the bubble (lattice diffusion, $D_{\ell}$ ). The relative rates of vapor: surface : lattice diffusion are given approximately by (Shewmon, 1964)

$$
\frac{D_{\mathrm{y}}}{2} \frac{\rho_{\mathrm{y}}}{\rho_{\mathrm{i}}}: \frac{D_{\mathrm{S}} \delta_{\mathrm{S}}}{r}: D_{\ell}
$$

where $\rho_{\mathrm{y}}$ and $\rho_{\mathrm{i}}$ are the densities of water molecules in the vapor and ice lattice, respectively, $\delta_{S}$ is the thickness of the high-diffusivity surface layer, and $r$ is the bubble radius. (More precisely, $r$ is the radius of the sphere with volume equal to the volume of the bubble in question. Bubbles in ice are sufficiently spherical that this distinction is not significant.) If we take a sample from Byrd Station, Antarctica, with a temperature of $-28^{\circ} \mathrm{C}$ and pore radius of about $0.3 \mathrm{~mm}$ (Gow, 1968) as a typical example, and we use the values of physical parameters listed at the beginning of this paper, then the ratio in statement (26) becomes

$$
10^{-12}: 10^{-17}: 10^{-16}
$$

and it is evident that we need worry only about vapor diffusion for the ice-air system. (Compression of bubbles with depth will decrease $D_{\mathrm{v}}$ and $r$, thus decreasing the vapor-diffusion term and increasing the surface-diffusion term in statement (27); however, the two terms would become equal only if bubbles were subjected to a pressure equivalent to an overburden of more than $50 \mathrm{~km}$ of ice and if no air dissolved in the ice lattice.)

Separation of a bubble migrating primarily by vapor diffusion from a boundary between two grains has been considered in some detail by Hsueh and Evans (1983). Where a grain boundary intersects a bubble, motion of the boundary causes the bubble to change shape so that the radius of curvature is longer for the leading edge than for the trailing edge (Fig. 3). The equilibrium vapor pressure varies directly with the radius of curvature, so a flux of molecules is established from the leading to the trailing edge, causing the bubble to move in the same direction as the boundary. Hsueh and Evans (1983) then calculated the maximum steady-state velocity of the bubble, $v_{\mathrm{b}}^{\mathrm{m}}$, assuming that it remains nearly spherical and that the mean free path 


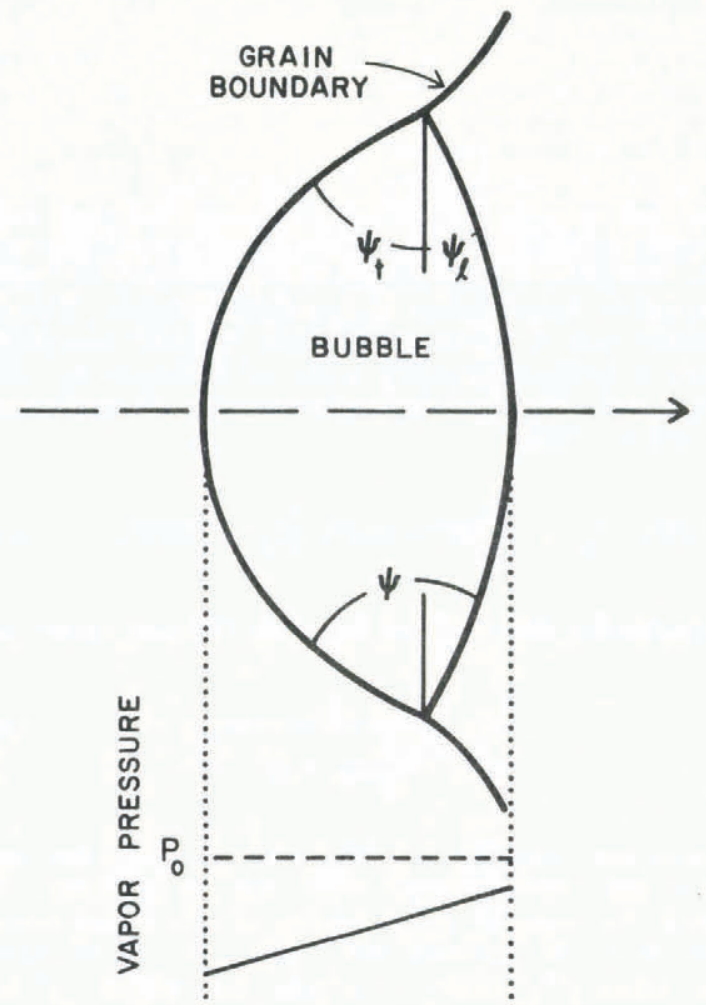

Fig. 3. Geometry used in model of bubble drag, after Hsueh and others (1982). Bubble and boundary are symmetric about the axis shown (dashed line) and moving in the direction indicated. The equilibrium dihedral angle is $\psi\left(=\psi_{t}+\psi_{f}\right)$ and $\psi_{t}=\pi / 2$ to maximize bubble velocity. Vapor pressure across the bubble is shown schematically, and $P_{0}$ is the equilibrium vapor pressure over a planar surface. Bubbles in ice are more nearly spherical than shown here.

of diffusing molecules is long compared to the bubble dimension; a boundary moving faster than $\nu_{\mathrm{b}}^{\mathrm{m}}$ will separate from an associated bubble.

Bubbles in ice are sufficiently spherical for this analysis, but the mean free path of water molecules diffusing through air at atmospheric pressure is about $10^{-7} \mathrm{~m}$ (Hobbs and Mason, 1964), whereas bubble radii typically exceed $10^{-4} \mathrm{~m}$. We thus must modify the expression of Hsueh and Evans (1983) to allow for diffusion of water molecules through air. The resulting expression for $v_{\mathrm{b}}^{\mathrm{m}}$ then moving at $v_{\mathrm{b}}^{\mathrm{m}}$ has an altitude of $1.06 \mathrm{r}$.) The equilibrium dihedral angle of a bubble in ice is about $\boldsymbol{\psi}=0.8 \pi$ Substituting these values into Equation (28) and simplifying yields

$$
v_{\mathrm{b}}^{\mathrm{m}}=\frac{0.128 m^{\prime} \Omega \gamma_{\mathrm{S}} P_{0} D_{c} r}{(k T)^{2} \rho_{\mathrm{i}}{ }_{\mathrm{c}}{ }^{3}}
$$

with the restriction that $r_{\mathrm{c}}=r$ above pore close-off. Thus, $v_{\mathrm{b}}^{\mathrm{m}} \propto 1 / r^{2}$ for pores at atmospheric pressure, but $v_{\mathrm{b}}^{\mathrm{m}} \propto r$ for closed bubbles undergoing compression.

In the high-velocity regime, the effect of bubbles is entirely analogous to the effect of microparticles. If the bubbles are randomly distributed, then the equations derived for the effect of microparticles in the high-velocity regime also describe the effect of bubbles.

The analysis of bubble-boundary separation presented above does not yield the bubble drag in low-velocity migration easily, so we use the older, phenomenological approximation, which has been discussed by Shewmon (1964), Kingery and Francois (1965), Nichols (1966, 1968), and Brook (1969), among others. Using the analysis of Shewmon (1964), the bubble-drag force in the low-velocity regime, $P_{\mathrm{b}}$, is

$$
P_{\mathrm{b}}=\frac{N_{\mathrm{b}}}{2 \pi R^{2}} F_{\mathrm{b}}
$$

where $N_{\mathrm{b}}$ is the number of bubbles per grain boundary, $2 \pi R^{2}$ is the area per grain boundary (the other $2 \pi R^{2}$ of a spherical grain is allocated to adjacent grains), and $F_{\mathrm{b}}$, the drag force per bubble, is given by

$$
F_{\mathrm{b}}=\frac{v \pi k T r^{3}}{\Omega}\left[\frac{\mathrm{D}_{\mathrm{y}}}{2} \frac{\rho_{\mathrm{y}}}{\rho_{\mathrm{i}}}+\frac{D_{\mathrm{s}} \delta_{\mathrm{s}}}{r}+\mathrm{D}_{\ell}\right]^{-1} \text {. }
$$

The vapor-diffusion term is dominant in Equation (31). Notice that the grain-boundary and bubble velocities are equal in the low-velocity regime, and that the bubble-drag force is velocity-dependent. For bubbles below the firn-ice transition, $D_{\mathrm{v}}$ varies with $r^{3}$ and $F_{\mathrm{b}}$ is independent of bubble size; however, if $D_{\mathrm{v}}$ is constant, then $F_{\mathrm{b}}$ varies with $r^{3}$ and small bubbles cause little drag.

We can use Equation (31) to rewrite Equation (30) as

$$
P_{\mathrm{b}}=M_{\mathrm{b}}^{-1} v
$$

where $M_{\mathrm{b}}$, the bubble mobility, is given by

$$
M_{\mathrm{b}}^{-1}=\frac{N_{\mathrm{b}}}{2 \pi R^{2}} \frac{\pi k T r^{3}}{\Omega}\left[\frac{D_{\mathrm{y}}}{2} \frac{\rho_{\mathrm{y}}}{\rho_{\mathrm{i}}}+\frac{D_{\mathrm{s}} \delta_{\mathrm{s}}}{r}+D_{\ell}\right]^{-1} \text {. }
$$

$$
\nu_{\mathrm{b}}^{\mathrm{m}}=\frac{D_{\mathrm{c}}}{\Delta x}\left[\frac{2 \pi m^{\prime}}{k T}\right]^{\frac{1}{2}}\left[\frac{r}{r_{\mathrm{c}}}\right]^{3}\left\{\frac{\mathrm{P}_{\mathrm{e}}}{\rho_{\mathrm{i}}} \sqrt{\frac{2 m^{\prime}}{\pi k T}}\left[\frac{2 \Omega \gamma_{\mathrm{s}}}{k T r}\right]\left(0.13 \psi^{2}-0.85 \psi+1.4\right)\right\}
$$

where $D_{\mathrm{c}}$ is the diffusivity of water molecules in air at pore close-off, $\Delta x$ is the characteristic diffusion distance, $m^{\prime}$ and $\Omega$ are the mass and volume of a water molecule, $k$ is Boltzmann's constant and $T$ is absolute temperature, $r$ is bubble radius and $r_{\mathrm{c}}$ is its value at pore close-off, $P_{0}$ is equilibrium vapor pressure over a planar ice surface, $\rho_{\mathrm{i}}$ is the density of ice, $\gamma_{\mathrm{s}}$ is the ice-air surface tension, and $\psi$ is the equilibrium dihedral angle where a grain boundary and bubble intersect. The expression in curly brackets is the original relation advanced by Hsueh and Evans (1983) and allows for the pressure difference arising from curvature difference across the bubble. The additional terms correct for the effect of air on diffusion and for the variation of diffusivity caused by compression of bubbles below the firn-ice transition; $r_{c}$ should be set equal to $r$ when air pressure is atmospheric. The diffusion distance, $\Delta x$, is on the order of $r$. (A cylindrical pore with volume and base equal to the volume and maximum cross-section of a pore
The general behavior of bubble drag is plotted in Figure $2 \mathrm{~b}$ and $\mathrm{c}$. The slope of the low-velocity regime in these figures is $M_{\mathrm{i}}^{-1} /\left(M_{\mathrm{i}}^{-1}+M_{\mathrm{b}}^{-1}\right)$ (see Equation (15)). When $M_{\mathrm{b}}=0$, bubbles do not migrate and the slope is zero; this is the case for microparticles. If $M_{\mathrm{b}}$ is small (Fig. 2b), then the low-velocity regime will exhibit little grain growth; however, if $M_{\mathrm{b}}$ is large (Fig. 2c), then low-velocity migration may approach the intrinsic case. In paper II (Alley and others, 1986), we show that Figure 2b applies to bubbles in ice and that Figure $2 \mathrm{c}$ applies to thermal grooves and small necks in firn. Remember that, in all cases, transition from low-velocity to high-velocity boundary migration (which occurs off-scale in Figure 2c) involves an increase in boundary velocity.

Figure $2 \mathrm{~b}$ and $\mathrm{c}$ are shown double-valued for some velocities because a boundary in the low-velocity regime collects bubbles as it migrates. Thus, a driving force large enough to cause high-velocity migration through uniformly 
distributed bubbles may be unable to cause separation from the extra bubbles accumulated during low-velocity migration.

\section{Impurity drag}

Dissolved impurities are the most important cause of extrinsic drag forces in many materials. Even a few parts per million of some solutes will reduce grain-boundary mobilities by orders of magnitude (Aust and Rutter, 1959; Rutter and Aust, 1960).

An impurity atom introduced into a regular lattice will cause strain in the lattice because of misfit in size and/or charge. A grain boundary is disordered relative to a lattice, so an impurity atom causes less strain in a grain boundary than in a regular lattice. There is thus an interaction energy, $U$, between an impurity atom and a grain boundary that causes the impurity to segregate to the grain boundary. For dilute systems such as glacial ice, the concentration of impurities in the boundary, $C_{\mathrm{b}}$, is related to the concentration in the lattice, $C_{\ell}$, by

$$
C_{\mathrm{b}}=C_{\ell} \exp \left(\frac{U}{k T}\right)
$$

where $U$ is positive for attraction between boundaries and impurities, and may be on the order of $10 \mathrm{kT}$ for strong interactions (Westengen and Ryum, 1978). (A boundary can be viewed crudely as a region transitional between liquid and solid. The limiting case of grain-boundary segregation then is seen to be the commonly observed phenomenon of solute segregation to a melt during solidification.)

For a grain boundary to migrate, it must either escape its associated impurity atmosphere by moving faster than the impurities can diffuse (high-velocity regime in Figure 2d) or it must drag the impurities along (low-velocity regime; Fig. 2d). The plot of actual versus intrinsic velocity for impurity drag is double-valued within a narrow range (Fig. 2d; Cahn, 1962), for the same reason that the bubble-drag plot is double-valued (see above). The transition velocity for escape from impurities has not been calculated exactly, but the value estimated by Cahn (1962) is several orders of magnitude faster than that observed in glacial ice or in most metallurgical experiments. We thus follow Higgins (1974) and Grey and Higgins (1973) in assuming that, during normal grain growth, the low-velocity regime obtains. The impurity drag force, $P_{S}$, then is estimated as (Cahn, 1962)

$$
P_{S}=\alpha C_{\ell} v
$$

where $C_{\boldsymbol{\ell}}$ is the concentration of impurities in the bulk lattice, $v$ is the grain-boundary velocity, and $\alpha$ is an interaction parameter between a grain boundary and impurities which depends on the concentration and diffusivity profiles of impurities in the immediate vicinity of the boundary. This parameter can be evaluated experimentally even though it cannot be calculated $a$ priori at present.

Because $P_{\mathrm{S}}$ is velocity-dependent, its effect is to reduce the grain-boundary mobility or increase the grain-boundary drag. Just as we did in Equation (16), we can use Equation (35) to rewrite Equation (1) as

$$
v=\frac{P}{M_{\mathrm{i}}^{-1}+\alpha C_{l}}
$$

where $M_{\mathrm{i}}$ is the intrinsic grain-boundary mobility. The term $\alpha C_{\ell}$ is thus the extrinsic drag of Equation (16).

The value of $C_{l}$ is constant in some systems, but may increase with grain growth under certain restricted circumstances. The variation of $C_{\ell}$ can be discussed most easily in terms of the grain-boundary partition coefficient, $k_{0}$, which we define as

$$
k_{0} \equiv \frac{C_{\mathrm{b}}}{C_{\ell}}\left[=\exp \left[\frac{U}{k T}\right]\right)
$$

where $C_{\mathrm{b}}$ is the impurity concentration in the boundary. The partition coefficient in solid-liquid systems may be concentration-dependent or concentration-independent, depending on the system and the range of concentrations considered (Gross and others, 1975[a], [b]); in the lattice/ grain-boundary system for ice, it is sufficiently accurate to consider $k_{0}$ to be a constant.

The total concentration of solute, $C_{\mathrm{T}}$, is fixed in a sample that is large relative to grain-size. We now make a first-order estimate of the distribution of this solute in the sample. Consider a spherical grain or "unit cell" of radius $R$ and impurity concentration $C_{\mathrm{T}}$ in such a sample. This grain is divided into a lattice region with impurity concentration $C_{\ell}$ and a surface boundary layer of thickness $\delta_{s}$, volume $4 \pi R^{2} \delta_{\mathrm{S}}$, and impurity concentration $C_{\mathrm{b}}$. Conservation of mass requires that

$$
4 \pi R^{2} \delta_{\mathrm{s}} C_{\mathrm{b}}+\left(\frac{4}{3} \pi R^{3}-4 \pi R^{2} \delta_{\mathrm{S}}\right) C_{l}=\frac{4}{3} \pi R^{3} C_{\mathrm{T}}
$$

or, substituting for $C_{\mathrm{b}}$ from Equation (37) and re-arranging,

$$
C_{\ell}=\frac{C_{\mathrm{T}}}{\frac{3 \delta_{\mathrm{S}}}{R}\left(k_{0}-1\right)+1} .
$$

We must now consider two cases. In the first, the surface layer is not saturated with solute and its thickness, $\delta_{\mathrm{S}}$, is fixed by the intrinsic nature of ice. In the second case, the surface layer is saturated with solute and $\delta_{s}$ increases as grains grow. (We follow Chaterjee and Jellinek (1971) in assuming that the surface layer is saturated when its composition, $C_{\mathrm{b}}$, equals the eutectic composition for the water-impurity system, $C^{\mathrm{e}}$.)

For $\delta_{s}$ fixed, Equation (39) shows that $C_{\ell}$ is nearly equal to $C_{\mathrm{T}}$ and independent of $R$ if $k_{0}$ is not extremely large. This case probably applies to most natural glacial ice relative to most impurities. For $\delta_{\mathrm{s}}$ constant and $k_{0} \gg 1$, $C_{\ell}$ varies directly with $R$ and is less than $C_{\mathrm{T}}$.

If the boundary composition equals the eutectic composition, then Equation (37) gives

$$
C_{\ell}=\frac{C^{\mathrm{e}}}{k_{0}} .
$$

Substituting this for $C_{\ell}$ in Equation (39) and solving for $\delta_{\mathrm{s}}$ as a function of grain radius then leads to

$$
\delta_{\mathrm{s}}(R)=\frac{C_{\mathrm{T} k_{0}}-C^{\mathrm{e}}}{3 C^{\mathrm{e}}\left(k_{0}-1\right)} R
$$

and the grain-boundary thickness is directly proportional to grain radius. (This idea was advanced first for ice by Chaterjee and Jellinek (1971).) This sort of behavior is likely only for highly impure materials, such as first-year sea ice.

For some systems, it has been suggested that vacancies supply an additional drag force analogous to the impurity drag force (Gleiter, 1979; Estrin and Lücke, 1981; Lücke and Gottstein, 1981). Calculations made following these authors indicate that vacancy drag should not have a significant effect on the slow, high-temperature migration of boundaries in ice, but uncertainties in the theories and in our knowledge of some physical quantities are large enough that significant vacancy drag is possible. If present, vacancy drag would reduce boundary mobility but not cause deviation from linear dependence of grain area on time.

\section{DISCUSSION AND CONCLUSIONS}

We have reviewed how microparticles, bubbles, and dissolved impurities can cause drag on grain growth in both high-velocity and low-velocity regimes and have considered both velocity-dependent and velocity-independent drag forces. Grain growth driven by boundary curvature in natural glacial ice typically occurs in the high-velocity regime relative to bubbles, the high-velocity regime relative 
to microparticles (see paper II), and the low-velocity regime relative to dissolved impurities. The transition from highvelocity migration to low-velocity migration occurs when the driving force for high-velocity grain growth is reduced to zero at grain radii $R_{\mathrm{m}}^{\mathrm{p}}$ for microparticles and $R_{\mathrm{m}}^{\mathrm{b}}$ for bubbles. Impurity drag in the low-velocity regime is proportional to grain-boundary velocity, so impurities reduce the grain-boundary mobility. by

Taking these together, grain growth in ice is described

$$
\frac{\mathrm{d} R}{\mathrm{~d} t}=\frac{\frac{16 \gamma}{81}\left[\frac{1}{R}-\frac{1}{R_{\mathrm{m}}}\right]}{M_{\mathrm{i}}^{-1}+\alpha C_{\ell}}
$$

where

$$
\frac{1}{R_{\mathrm{m}}} \equiv \frac{1}{R_{\mathrm{m}}^{\mathrm{p}}}+\frac{1}{R_{\mathrm{m}}^{\mathrm{b}}}
$$

The value of $R_{\mathrm{m}}^{\mathrm{p}}$ is given by Equations (21) and (22), and $R_{\mathrm{m}}^{\mathrm{b}}$ is also given by Equations (21) and (22) in the highvelocity regime.

A number of observations should be made regarding Equation (42). The terms $1 / R_{\mathrm{m}}$ and $\alpha C_{\ell}$ are identically zero in pure, fully densified ice, and Equation (42) then predicts linear increase with time of the cross-sectional area of grains. This is also predicted if impurities are present but $C_{l}$ is independent of $R$, and if $R_{\mathrm{m}}$ is proportional to $R$. Deviation from linear increase of grain area with time occurs if $C_{\ell}$ depends on $R$ and $\propto C_{l}$ is significant or if $R_{\mathrm{m}}$ is not linearly dependent on $R$ and $1 / R_{\mathrm{m}}$ is significant.

Finally, we should re-emphasize that our analysis is restricted to cold ice. If the temperature of the ice-impurity system rises above the melting point of the impure grain boundaries, then liquid will form along the boundaries. This will increase diffusivities and allow Ostwald ripening of grains to occur through the liquid matrix (Fischmeister and Grimvall, 1973). Under such conditions, an increase in impurity content will increase the amount of liquid present and increase the rate of grain growth; thus, Equation (42) will not apply in high-temperature, impure systems.

Although most of the theories presented here are still under active development, the general ideas seem well established. We are now in a position to assess qualitatively, and of ten quantitatively, how different factors affect rates of grain growth in natural glacial ice. We do so in the following paper.

\section{ACKNOWLEDGEMENTS}

This work was funded in part by the U.S. National Science Foundation under grant DPP-8315777. We thank J.F. Bolzan, R.H. Dott, jr, P. Duval, A.J. Gow, M. Hillert, J.W. Valley, H.F. Wang, and I.M. Whillans for reading early versions of this manuscript, E. Mosley-Thompson for access to unpublished data, and A.N. Mares and S.H. Smith for manuscript preparation. This is contribution No. 432 of the Geophysical and Polar Research Center, University of Wisconsin-Madison.

\section{REFERENCES}

Alley, R.B., and others. 1986. Grain growth in polar ice: II. Application, by R.B. Alley, J.H. Perepezko, and C.R. Bentley. Journal of Glaciology, Vol. 32, No. 112, p. 425-33.

Anderson, M.P., and others. 1984. Computer simulation of grain growth - I. Kinetics, by M.P. Anderson, D.J. Srolovitz, G.S. Grest, and P.S. Sahni. Acta Metallurgica, Vol. 32, No. 5, p. 783-91.

Anderson, M.P., and others. 1985. Grain growth in three dimensions: a lattice model, by M.P. Anderson, G.S. Grest, and D.J. Srolovitz. Scripta Metallurgica, Vol. 19, No. 2, p. 225-30.
Ashby, M.F., and Centamore, R.M.A. 1968. The dragging of small oxide particles by migrating grain boundaries in copper. Acta Metallurgica, Vol. 16, No. 9, p. 1081-92.

Ashby, M.F., and others. 1969. The interaction of crystal boundaries with second-phase particles, by M.F. Ashby, J. Harper, and J. Lewis. Transactions of the Metallurgical Society of AIME, Vol. 245, No. 3, p. 413-20.

Aust, K.T., and Rutter, J.W. 1959. Temperature dependence of grain-boundary migration in high-purity lead containing small additions of tin. Transactions of the Metallurgical Society of AIME, Vol. 215, No. 4, p. 820-31.

Brook, R.J. 1969. Pores and grain growth kinetics. Journal of the American Ceramic Society, Vol. 52, No. 6, p. 339-40.

Cahn, J.W. 1962. The impurity-drag effect in grain boundary motion. Acta Metallurgica, Vol. 10, No. 9, p. 789-98.

Chatterjee, A.K., and Jellinek, H.H.G. 1971. Calculation of grain-boundary thickness in polycrystalline ice of low salinity. Journal of Glaciology, Vol. 10, No. 59, p. 293-97.

Colbeck, S.C. 1979. Grain clusters in wet snow. Journal of Colloid and Interface Science, Vol. 72, No. 3, p. 371-84.

Colbeck, S.C. 1982. Growth of faceted crystals in a snow cover. CRREL Report 82-29.

Duval, P. 1985. Grain growth and mechanical behaviour of polar ice. Annals of Glaciology, Vol. 6, p. 79-82.

Duval, P., and Lliboutry, L. 1985. Superplasticity owing to grain growth in polar ices. Journal of Glaciology, Vol. 31, No. 107 , p. 60-62.

Duval, P., and Lorius, C. 1980. Crystal size and climatic record down to the last ice age from Antarctic ice. Earth and Planetary Science Letters, Vol. 48, No. 1, p. 59-64.

Estrin, Y., and Lücke, K. 1981. Grain boundary motion - II. The effect of vacancy production on steady state grain boundary motion. Acta Metallurgica, Vol. 29, No. 5, p. 791-99.

Fischmeister, H., and Grimvall, G. 1973. Ostwald ripening - a survey. Materials Science Research, Vol. 6, p. 119-49.

Gleiter, H. 1979. Vacancy drag - the generation of vacancies by interface migration. Acta Metallurgica, Vol. 27, No. 11, p. 1749-54.

Gow, A.J. 1968. Bubbles and bubble pressures in Antarctic glacier ice. Journal of Glaciology, Vol. 7, No. 50, p. 167-82.

Gow, A.J. 1969. On the rates of growth of grains and crystals in south polar firn. Journal of Glaciology, Vol. 8, No. 53 , p. 241-52.

Gow, A.J., and Williamson, T. 1976. Rheological implications of the internal structure and crystal fabrics of the West Antarctic ice sheet as revealed by deep core drilling at Byrd Station. CRREL Report 76-35.

Grey, E.A., and Higgins, G.T. 1973. Solute limited grain boundary migration: a rationalization of grain growth. Acta Metallurgica, Vol. 21, No. 4, p. 309-21.

Gross, G.W., and others. 1975[a]. Concentration dependent solute redistribution at the ice/water phase boundary. I. Analysis, by G.W. Gross, C. McKee, and C.-h. Wu. Journal of Chemical Physics, Vol. 62, No. 8, p. 3080-84.

Gross, G.W., and others. 1975[b]. Concentration dependent solute redistribution at the ice/water phase boundary. II. Experimental investigation, by G.W. Gross, C.-h. Wu, L. Bryant, and C. McKee. Journal of Chemical Physics, Vol. 62 , No. 8 , p. $3085-92$.

Hellman, P., and Hillert, M. 1975. On the effect of second-phase particles on grain growth. Scandinavian Journal of Metallurgy, Vol. 4, No. 5, p. 211-19.

Higgins, G.T. 1974. Grain-boundary migration and grain growth. Metal Science, Vol. 8, No. 5, p. 143-50.

Hillert, M. 1965. On the theory of normal and abnormal grain growth. Acta Metallurgica, Vol. 13, No. 3, p. 227-38.

Hobbs, P.V. 1974. Ice physics. Oxford, Clarendon Press.

Hobbs, P.V., and Mason, B.J. 1964. The sintering and adhesion of ice. Philosophical Magazine, Vol. 9, Ser. 8, No. 98, p. 181-97. 
Hsueh, C.H., and Evans, A.G. 1983. Microstructure evolution during sintering: the role of evaporation/condensation. Acta Metallurgica, Vol. 31, No. 1, p. 189-98.

Hsueh, C.H., and others. 1982. Overview 22: microstructure development during final/intermediate stage sintering - I Pore/grain boundary separation, by C.H. Hsueh, A.G. Evans, and R.L. Coble. Acta Metallurgica, Vol. 30, No. 7, p. 1269-79.

Kingery, W.D., and François, B. 1965. Grain growth in porous compacts. Journal of the American Ceramic Society, Vol. 48 , No. 10 , p. 546-47.

List, R.J., comp. 1958. Smithsonian meteorological tables. Smithsonian Miscellaneous Collections, Vol. 114.

Louat, N.P. 1974. On the theory of normal grain growth. Acta Metallurgica, Vol. 22, No. 6, p. 721-24.

Lücke, K., and Gottstein, G. 1981. Grain boundary motion - I. Theory of vacancy production and vacancy drag during grain boundary motion. Acta Metallurgica, Vol. 29, No. 5, p. 779-89.

Mullins, W.W. 1986. The statistical self-similarity hypothesis in grain growth and particle coarsening. Journal of Applied Physics, Vol. 59, No. 4, p. 1341-49.

Nes, E., and others. 1985. On the Zener drag, by E. Nes, N. Ryum, and O. Hunderi. Acta Metallurgica, Vol. 33, No. 1 , p. 11-22.

Nichols, F.A. 1966. Theory of grain growth in porous compacts. Journal of Applied Physics, Vol. 37, No. 13, p. 4599-602.

Nichols, F.A. 1968. Further comments on the theory of grain growth in porous compacts. Journal of the American Ceramic Society, Vol. 51, No. 8, p. 468-69.
Paterson, W.S.B. 1981. The physics of glaciers. Second edition. Oxford, etc., Pergamon Press. (Pergamon International Library.)

Rutter, J.W., and Aust, K.T. 1960. Kinetics of grain boundary migration in high-purity lead containing very small additions of silver and gold. Transactions of the Metallurgical Society of AIME, Vol. 218, No. 4, p. 682-88.

Shewmon, P.G. 1964. The movement of small inclusions in solids by a temperature gradient. Transactions of the Metallurgical Society of AIME, Vol. 230, No. 5, p. 1134-37.

Smith, C.S. 1948. Grains, phases, and interfaces: an interpretation of microstructure. Transactions of the Metallurgical Society of AIME, Vol. 175, p. 15-51.

Srolovitz, D.J., and others. 1984. Computer simulation of grain growth - II. Grain size distribution, topology, and local dynamics, by D.J. Srolovitz, M.P. Anderson, P.S. Sahni, and G.S. Grest. Acta Metallurgica, Vol. 32, No. 5, p. 793-802.

Stephenson, P.J. 1967. Some considerations of snow metamorphism in the Antarctic ice sheet in the light of ice crystal studies. (In Ōura, H., ed. Physics of snow and ice: international conference on low temperature science ... 1966. .. Proceeedings, Vol. 1, Pt. 2. [Sapporo], Institute of Low Temperature Science, Hokkaido University, p. 725-40.)

Verhoeven, J.D. 1975. Fundamentals of physical metallurgy. New York, John Wiley and Sons.

Westengen, H., and Ryum, N. 1978. On the effect of solute atoms on grain-boundary migration. Philosophical Magazine, Ser. A, Vol. 38, No. 3, p. 279-95. 